\title{
Different Learning Style Preferences of Male and Female Iranian Non-academic EFL Learners
}

\author{
Mohammad Bagher Shabani ${ }^{1}$ \\ ${ }^{1}$ Imam Khomeini International University, Qazvin, Iran \\ Correspondence: Mohammad Bagher Shabani, Assistant Professor, Imam Khomeini International University, \\ Qazvin, Iran. E-mail: Shabani_m_b@yahoo.com
}

Received: September 12, 2011 Accepted: July 9, 2012 Online Published: July 30, 2012

doi:10.5539/elt.v5n9p127 URL: http://dx.doi.org/10.5539/elt.v5n9p127

\begin{abstract}
Learning, as the most important concept in education, demands urgent attention. Individuals have different learning styles and awareness of these individual differences by both students and teachers is vital for the most effective use of the methodologies and pedagogical strategies available to teachers in maximizing learning success. Despite the groundswell of literature on learning styles and academic performance, little research has focused on the differences between learning styles of academic and non-academic learners in the Iranian context. This study sought to investigate the style preferences (LSPs) of Iranian non-academic EFL learners and to examine the differences between the LSPs of male and female learners. To do so, 132 students studying English as a foreign language at language institutes participated in the study. Paragon Learning Style Inventory (PLSI) was employed to examine the LSPs of the participants. The results were reported descriptively. In order to check the statistical significance of the observed differences between male and female students, a set of Chi-squares were carried out using Statistical Package for the Social Sciences (SPSS), version 18. The findings supported the claim that there are discrepancies between the LSPs of male and female students. These findings connote that there is a call for awareness of learners' individual differences, mainly their LSPs in the attempt to idealize the outcomes of TEFL in language institutes in Iran. The findings of this study can assist course developers and syllabus designers base their work on the individual differences of the learners in order to meet the requirement of all learners as much as possible.
\end{abstract}

Keywords: Learning Style Preference, LSP, Iranian non-academic EFL learners, PLSI

\section{Introduction}

Several factors can affect the success of foreign language learning apart from teaching methodologies and pedagogical strategies employed in the instruction of foreign languages. These factors include learners' interest, motivation, learning style preferences (LSP), and personality trait, among others. Learning style preference, as claimed by some educators and researchers, is one of the main factors determining the success of the process of foreign language teaching and learning. A student's LSP refers to the way he/she responds to stimuli in a learning context, and to the student's specific way of acquiring knowledge.

As shown by several studies, people have different learning styles. Considering the variety of learning style preferences among students, the most effective mode of instruction tends to vary for different contexts. This diversity leads to the need for diverse teaching styles on the part of teachers and instructors in order to provide a successful instruction. As Felder (1993) states, the alignment between students' learning styles and instructors' teaching styles leads to better recall and understanding as well as to more positive post-course attitudes.

A considerable body of research has been conducted with a focus on LSP in the fields of TEFL (Teaching English as a Foreign Language) and TESL (Teaching English as a Second Language). A branch of this body of research attempted to describe and illustrate the LSP differences among different groups of learners such as male and female learners, EFL and ESL learners, and learners from different levels of knowledge, varied fields of study, age groups and different nationalities (e.g. Reid, 1987; Melton, 1990; Kang and Shumin, 1999).

In the Iranian context, several studies can be found with a focus on learning styles and their eminence in teaching English as a foreign language (Riazi \& Riasati, 2007; Noora, 2008; Soltani, 2008; Zamanzade, Valizade, Fathi Azar \& Aminaie, 2008). However, despite the crucial role of learners' learning styles awareness in providing a 
successful instruction, little if any attention has been paid to the students' individual differences of learning styles in designing syllabi and EFL courses for the students studying English as a foreign language in both academic and non-academic language institutions. This can be deemed as one of the factors hindering ultimate goals of TEFL in Iran. Having this in mind and considering the significance of LSPs, the present research sought to investigate the learning style preferences among male and female Iranian nonacademic EFL learners. The findings of this study can assist course developers and syllabi designers to base their work on the individual differences of the learners in order to meet the requirements of all learners as much as possible.

To achieve the aforementioned goal, 132 students studying English as a foreign language participated in the study. The participants were selected from four language institutes, namely Iran Language Institute, Parse Language Institute, Marefat Language Institute, and Zabankade. In order to assess the LSPs of the participants a questionnaire known as Paragon Learning Style Inventory (PLSI, 1998, See Appendix A) was applied. Data analysis was carried out using Statistical Package for the Social Sciences (SPSS) software, version 18. The findings of the study supported the claim that there are discrepancies between the LSPs of male and female learners which connotes that there is a call for awareness of learners' individual differences, mainly their LSPs in the attempt to idealize the outcomes of TEFL in non-academic settings in Iran.

\subsection{Learning Style}

Several definitions have been offered for learning styles. Ellis (2001) defines learning style as the consistent pattern of behavior and performance by which an individual approaches educational experiences. Sternberg (2001) sees learning style as a habitual pattern or preferred way of doing something that is consistent over long periods of time and across a variety of activities. For Dybvig (2004), learning style is the way a person processes, internalizes, and studies new and challenging materials. According to Vester (2005), learning style is the more or less consistent way in which a person perceives, conceptualizes, organizes, and recalls information. What all these definitions have in common is that learning styles are individual preferences in learning situations.

\subsection{The Importance of Learning Style Awareness in Education}

Both learners' and teachers' awareness of the individual differences among students can be of great help in successfully leading them through the process of instruction. Without sufficient knowledge about students' style preferences, teachers are not likely to provide the required instructional variety to match the diversity that exists among students in a class. According to Felder and Brent (2004), an understanding of the students' learning styles can help educators adjust their teaching styles to address the students' needs. Kaplan and Kies (1993) have also stressed the utility of learning style awareness on the part of teachers and learners.

\section{This Study}

Recently, there has been a major shift in the field of foreign language instruction. Traditional teacher-centered approaches are replaced with more learner-centered ones and learner preferences have gained increasing notice; however, learner preferences are rarely addressed in planning language courses and designing syllabi in the Iranian context in both academic and nonacademic settings. Perhaps, one of the main sources of the students' frustration and lack of success in learning foreign languages at Iranian educational system of universities and foreign language institutions is the instructors' and syllabus designers' unawareness of the students' learning styles and the effect LSPs can have on their acquisition and attitude toward their learning experience.

Obviously, planning lessons and designing syllabi on the basis of individual differences of students is very difficult or even impossible and would cost much time and money. Further, in the Iranian educational settings, students are not allowed to participate in decision-makings of their courses. Considering all these, the present study attempted to identify the learning style preferences of Iranian non-academic students and to investigate the relationship between their LSPs and gender. This study sought to answer the following questions:

1. What are the learning style preferences of Iranian nonacademic EFL learners as measured by the Paragon Learning Style Inventory?

2. Is there any relationship between Iranian nonacademic EFL learners' learning style preferences and their gender?

\subsection{Rationale for the Study}

It is hoped that the findings of this study will enhance the syllabus designers', decision makers' and educators' awareness of learning style variations among university students and help them as a guide for matching the teaching styles to students' learning styles. Moreover, the results can increase the students' awareness of their learning style preferences, so that they can modify their learning styles and develop additional ones in order to 
enhance their course achievement.

\subsection{Participants}

In order to achieve the goal of investigating the distinctions in LSPs of male and female learners in the Iranian context, 132 Iranian EFL learners studying English as a foreign language participated in the study. The participants were selected from four language institutes, namely Iran Language Institute, Parse Language Institute, Marefat Language Institute, and Zabankade in Hamedan. 68 of the participants were female and 64 were male. Their age ranged from 18 to 22 . The criterion for selection of the students was the age range. The participants had attended English classes for 2-4 years and were chosen from pre-intermediate to upper-intermediate levels.

\subsection{Instrument}

This study utilized Paragon Learning Style Indicator (PLSI, See Appendices A) in order to examine the participants' LSPs. PLSI is a reliable and validated inventory that examine the participants' learning styles. The PLSI is a 48 item learning style inventory, developed by Shindler and Yang (2002) specifically for use in educational settings with students aged eight or older. The PLSI is based on the personality test called the Myers-Briggs Type Indicator (MBTI), which is based on Jung's theories of personality (Jung 1923). The MBTI was developed by Briggs-Myers in 1962 to classify people along the four Jungian psychological learning dimensions, giving a measure of cognitive and perceptual preferences (Shindler and Yang, 2002).

The instrument measures four dimensions of a person's personality: Extraversion (E) vs. Introversion (I), Sensing (S) vs. Intuitive, Thinking vs. feeling, and Judging vs. Perceiving (P) which are defined in Table 1. Each of the four dimensions is independent of the other three, and relationships among the four bipolar dimensions provide 16 possible types: ISTJ, ISFJ, INFJ, INTJ, ISTP, ISFP, INFP, INTP, ESTP, ESFP, ENFP, ENTP, ESTJ, ESFJ, ENFJ, and ENTJ.

Table 1. Characteristics of learning styles for each dimension

\begin{tabular}{lll}
\hline Learning Style & Function & Characteristics \\
\hline $\begin{array}{l}\text { Extrovert } \\
\text { Introvert }\end{array}$ & $\begin{array}{l}\text { Concerns the way people deal } \\
\text { with other people and ideas }\end{array}$ & $\begin{array}{l}\text { Learn through the outer world of people, things and actions } \\
\text { Learn through the inner world of ideas and impressions }\end{array}$ \\
\hline $\begin{array}{l}\text { Sensing } \\
\text { Intuitive }\end{array}$ & $\begin{array}{l}\text { Deals with how people } \\
\text { take in information }\end{array}$ & $\begin{array}{l}\text { Uses senses to draw on what is real } \\
\text { Use imagination to envision what is possible }\end{array}$ \\
\hline Thinking & $\begin{array}{l}\text { Concerns how people } \\
\text { make decisions }\end{array}$ & Make decisions based on logic \\
Feeling & Concerns the lifestyle & Make decisions based on people and their actions \\
\hline $\begin{array}{l}\text { Judging } \\
\text { Perceiving }\end{array}$ & a person prefers & $\begin{array}{l}\text { Have preference for living a planned life } \\
\text { Spontaneous and flexible }\end{array}$ \\
\hline
\end{tabular}

\subsection{Procedure and Data Collection}

In order to collect the required data, PLSI (See Appendices A) was administered to the participants during the summer term and then the questionnaires were examined by the researcher. Each item of the PLSI relates to one of the four dimensions of learning style and was scored according to which learning style is preferred. The score for each dimension was then obtained by summing the individual scores for all questions for that dimension. Doing so, the LSPs of participants were at hand for further investigation. The analysis of the quantitative data involved a number of statistical procedures, namely, descriptive statistics and Chi-square. Data analysis was carried out using Statistical Package for the Social Sciences (SPSS) software, version 18.

\section{Results}

\subsection{Learning Style Preferences}

The first question was set as 'What are the learning style preferences of Iranian university students as measured by the Paragon Learning Style Inventory?' In order to answer this question, PLSI was administered to 132 Iranian non-academic EFL students to determine their learning style preferences. Then, descriptive statistics were used to determine the frequencies and percentages of the learners with each of the eight learning styles. The results are illustrated in table 2 . 
Table 2. The distribution of LSPs among participants

\begin{tabular}{lll}
\hline SP & Number & Percent \\
\hline Extrovert & 82 & $62.12 \%$ \\
Introvert & 50 & $37.88 \%$ \\
Sensing & 94 & $71.21 \%$ \\
Intuitive & 38 & $28.79 \%$ \\
Thinking & 78 & $59.09 \%$ \\
Feeling & 54 & $40.91 \%$ \\
Judging & 98 & $74.24 \%$ \\
Perceiving & 34 & $25.76 \%$ \\
\hline
\end{tabular}

Figure 1 also represents the distribution of preferences on four scales of PLSI. It should be noted that the figure shows the distribution based on percentages.

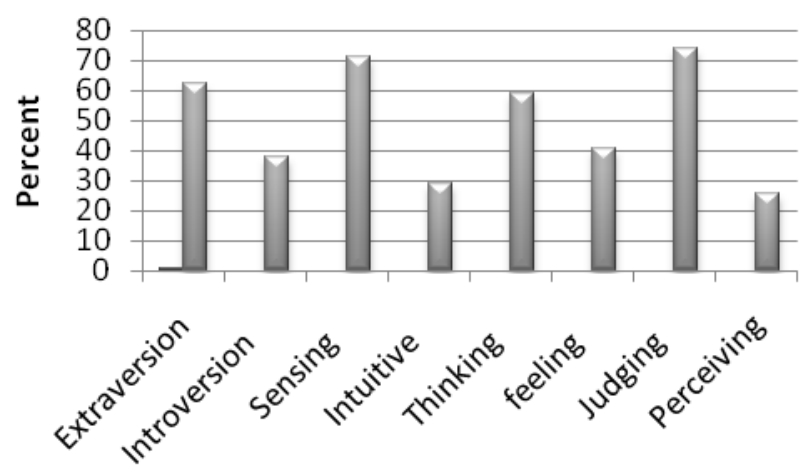

PLS

Figure 1. The Distribution of Learning Style Preferences

As Table 2 and Figure 1 illustrate, there are considerable diversities in the learning style preferences of Iranian non-academic EFL learners as examined by PLSI. As the findings indicate, the majority of the sample in this study has showed a strong preference for two dimensions of learning style, namely Sensing and Judging. It means that most of the participants tend to be interested in what their five senses show them, that is what exists in the present. They use the senses to draw on what is taught to them. This implies that the instructors should attempt to teach EFL learners in a way that they can receive as much as possible through their senses.

They also like to have things decided; life is likely to be planned and orderly for them. Most of the students have preference for a planned teaching syllabus. It implies that exposing them to non-planned and flexible syllabi will have destructive effect on their learning. The participants are more extrovert rather than introvert. It entails that in order to learn better, they need to communicate with the outer world and people. Providing communication with other learners and native speakers can be a great help in promoting learning.

\subsection{Learning Style Preferences and Gender}

The second question was stated as: 'Is there any relationship between Iranian non-academic EFL learners' learning style preferences and their gender?' To answer this question, the participants were divided into two groups of male and female and the number and percentage of the groups who preferred each learning style were determined. The results are shown in table 3.

Table 3. Descriptive statistics for frequency distribution of learners' LSPs based on gender

\begin{tabular}{lllll}
\hline LSP & Female $(\mathrm{n})$ & Female $(\%)$ & Male $(\mathrm{n})$ & Male $(\%)$ \\
\hline Extrovert & 42 & 61.76 & 25 & 39.07 \\
Introvert & 26 & 38.24 & 39 & 60.93 \\
\hline Sensing & 53 & 77.94 & 37 & 57.81 \\
Intuitive & 15 & 22.06 & 31 & 42.19 \\
\hline Thinking & 41 & 60.29 & 23 & 35.93 \\
Feeling & 27 & 39.71 & 41 & 64.07 \\
\hline Judging & 59 & 86.76 & 46 & 71.87 \\
Perceiving & 9 & 13.24 & 18 & 28.13 \\
\hline
\end{tabular}


The following figures also represent the preferences on four scales of PLSI. It should be noted that, because of the nature of the index, the results are illustrated scale by scale.

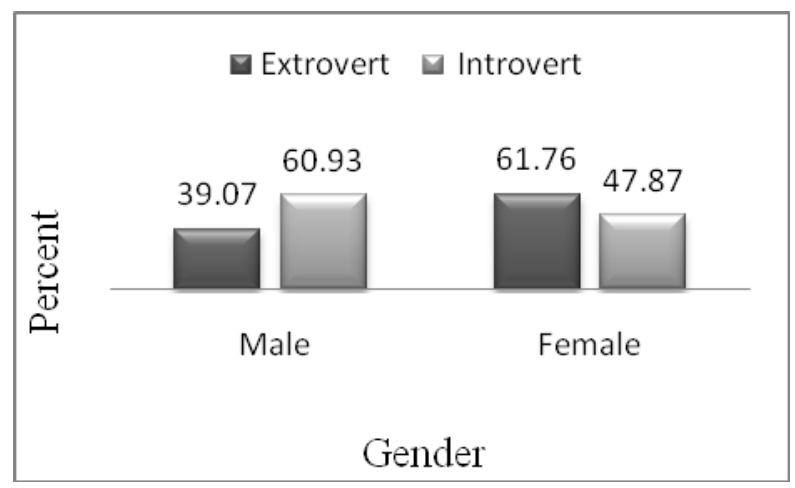

Figure 2. Comparing Students' Preferences based on Gender on Extrovert/Introvert Scale

As illustrated in Figure 2, in the case of the first scale (Extrovert-Introvert), male students show a preference for Introversion rather than Extroversion. This means that male students tend to relate easily to the inner world of ideas and impressions; while, the female participants prefer the Extroversion dimension, it means that females tent to relate easily to the outer world of people and things. These differences show the need for different teaching styles to students from two genders.

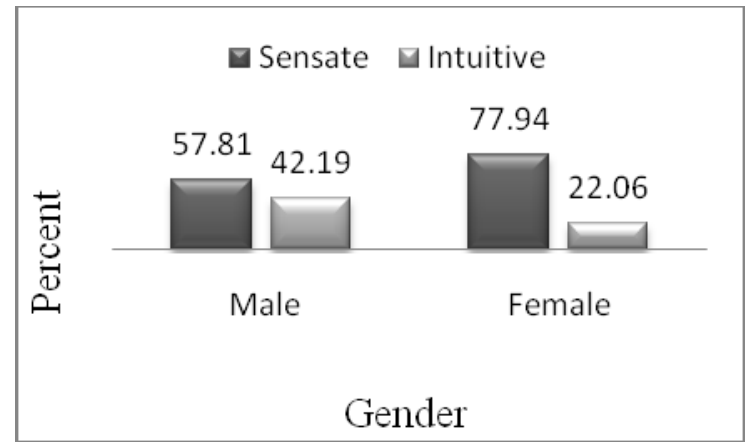

Figure 3. Comparing students' preferences based on gender on sensate/intuitive scale

In the case of the second scale (Sensing-Intuitive), as shown in figure 3, both groups express their preference for Sensing dimension. Of course, this preference is stronger for female students. As previously mentioned, this means that they tend to be interested in what the five senses show them. Although, students of both genders show a tendency for sensing learning style, females tend to be more dependent on what they gain through their five senses and this has implications for teaching females.

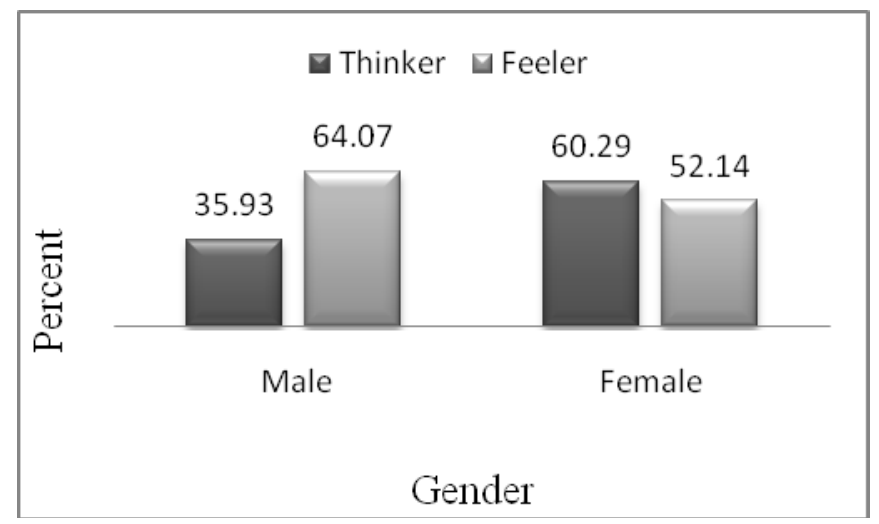

Figure 4. Comparing students' preferences based on gender on feeler/ thinker scale 
As the results shown in figure 4 indicate, for the third scale, (Thinking-Feeling), a moderate majority of male students prefer the feeling dimension rather that the Thinking one. It means that tend to base decisions on values and people-centered concerns. In the case of female students, there seems to be little difference between those who prefer feeling learning style and the thinking one. However, female students prefer thinking dimension rather than the feeling one. This means that they tend to base decisions on objective analysis and logic.

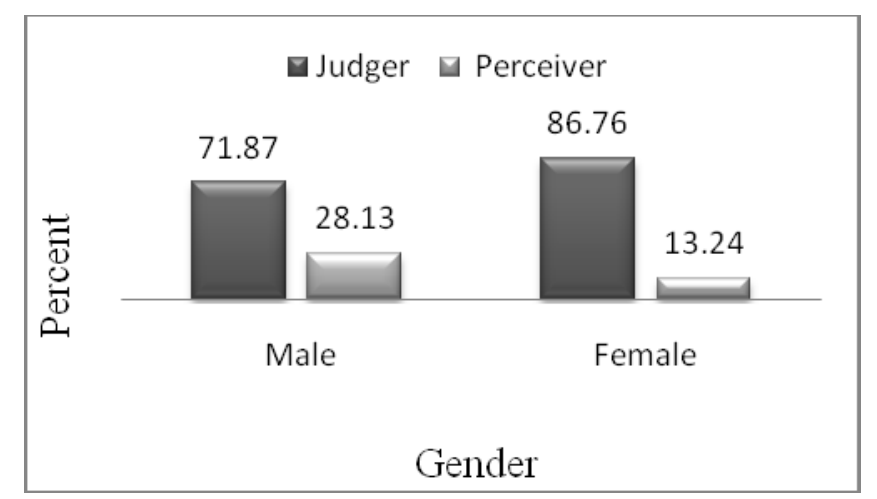

Figure 5. Comparing Students' Preferences based on Gender on Judger/Perceiver Scale

As shown in figure 5, for the forth scale (Judging-Perceiving), the male participants express a fairly strong preference for Judging dimension. It means that they tend to like to have things decided. The female participants also show the same preference; though, their preference is stronger than the males. It implies that both groups tend to prefer to be taught in a planned and orderly way.

In conclusion, it can be claimed that male students are more Introvert, Sensate, Feeler, and Judger; while female students tend to be more Extrovert, Sensate, Thinker, and Judger. In order to examine the significance of the observed differences between the learning style preferences of the two genders, the obtained data were subjected to Chi-square computation using SPSS software, version 18. The following tables represent the Chi-square results for four scales.

Table 4. Chi-square Results for LSP in Terms of Gender

\begin{tabular}{|c|c|c|c|c|c|c|c|c|}
\hline & 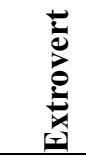 & 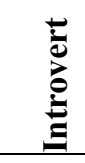 & 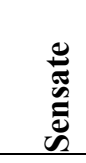 & 总 & 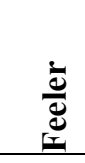 & 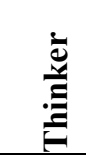 & 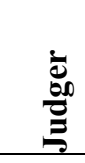 & 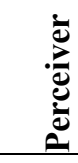 \\
\hline Chi-square & 4.31 & 2.60 & 2.84 & 5.56 & 5.06 & 2.88 & 1.61 & 3.00 \\
\hline df & 1 & 1 & 1 & 1 & 1 & 1 & 1 & 1 \\
\hline Sig. & $.03^{*}$ & .10 & .09 & $.01^{*}$ & $.02^{*}$ & .09 & .20 & .08 \\
\hline
\end{tabular}

\section{*= Statistically Significant}

As indicated in Table 4, merely the observed differences for the three scales of Extroversion, Intuition, and Thinking are statistically significant $(\mathrm{p}<.05)$. Considering the results, it can be claimed that male and female participant have been observed to have different learning styles.

\section{Conclusion}

The present study intended to identify the learning style preferences of Iranian university students and to investigate the relationship between their LSPs, gender, and field of study. With reference to the statistical procedures employed and their results, it can be concluded that Iranian non-academic EFL learners use different learning styles as measured by the Paragon Learning Style Inventory (PLSI) (1998), with the majority of them applying Sensate and Judger styles. This means that they are more interested in what their five senses show them rather than what their imagination tells them. It also implies that they are less interested in what exists at present rather than what can exist in the future. They also like to have things decided; life is likely to be planned and orderly for them rather than flexible and spontaneous. 
Further, the results of this study indicated that there are a number of similarities and differences in the learning styles preferred by the male and female participants. Both groups of the participants intended to be more sensate than intuitive. In addition, both groups preferred the Judging dimension over the Perceiving one. However, there are some differences. First, the female participants tend to be more Extrovert; while, the male students preferred the second dimension and tend to be more Introvert. Second, the male participangts showed a great preference for feeling dimension of the Feeling-Thinking scale, but the female students preferred the latter dimension more. Of course, it should be mentioned that there was only a slight difference (4.28\%) in the preference of the female students between these two dimensions. Having these differences in mind, it can be claimed that there seems to be a relationship between the learning styles used by students and their gender. In view of the observed differences between male and female participants regarding their LSPs, it is concluded that these groups require distinct teaching styles and syllabi in order to achieve the ultimate goals of onstruction.

It is hoped that the findings of this study can be used to improve the teaching practice and the performance of students. In view of the results of this study, it may prove beneficial to consider learning style preferences when designing and teaching courses to maximize learning success. As mentioned earlier, it is quite difficult determine individual learning styles of the students, dividing them into classes based on their learning styles, and teaching them accordingly. However, the teachers can address each learning style at least some of the time in their teaching. This way, the students' positive attitude toward the courses would also be promoted.

\section{Further Research}

Further research is required to be conducted with larger samples to check whether the same results will be gained. Similar research can also be done in Iranian academic settings to check the claims. Moreover, considering the significant role of students' learning styles, more research seems to be required to investigate the relationship between learning styles and teaching styles. In conducting these studies, other learning style batteries would be applied to investigate the discrepancy of learning style preferences among both academic and non-academic EFL learners.

\section{References}

Claxton, C., \& Murrel, P. (1987). Learning styles: Implications for improving educational practice. (ASHERIC Higher Education Report, No. 4). College Station, TX: ASHE.

Dybvig, T. (2004). Learning styles. Retrieved June 1, 2010, from http://www.tresadybvig.com/learsty.htm

Ellis, A. K. (2001). Research on educational innovations ( $3^{\text {rd }}$ ed.). New York: Eye on education, Inc.

Felder, R. M., \& Brent, M. (2004). Understanding students' differences. Journal of Engineering Education, 94(1), 57-72.

Kang, \& Shumin. (1999). Learning Styles: Implications for ESL/EFL Instruction. Forum, 37(4), 67-82.

Kaplan, E. G., \& Kies, D. E. (1993). Together: Teaching styles and learning styles in improving college instruction. College Student Journal, 24(4), 509-513.

Lin, Hsiang-Pao, \& Shen, and Shan-shan. (1996). Perceptual Learning Style Preferences for EFL Students in Junior Colleges in Taiwan.

Liyanage, I., Grimbeek, P., \& Birch, G. (2004). Computing Eysenck's Personality Types: A Closer Look at the Standard Method.

Melton, C. D. (1990). Bridging the cultural gap: A study of Chinese students' learning style preferences. RELC Journal, 21(1), 29-54. http://dx.doi.org/10.1177/003368829002100103

Noora, A. (2008). Iranian undergraduates non-English majors' language learning preferences. GEMA Online Journal of Language studies, 8(2), 33-44.

Reid, J. M. (1987). The learning style preferences of ESL students. TESOL quarterly, 21(1), 87-92. http://dx.doi.org/10.2307/3586356

Riazi, A., \& Riasati, M. J. (2007). Language learning style preferences: A student's case study of Shiraz EFL institutes. Asian EFL Journal, 9(1), Article 6.

Soltani, N. (2008). Investigation of cultural learning styles among Iranian Kurdish and Persian EFL learners. Unpublished master's thesis, Ilam University, Iran.

Sternberg, R. J. (2001). Epilogue: Another mysterious affair at styles. In R. J. Sternberg, \& L. F. Zhang (Eds.), Perspectives on thinking, learning, and cognitive styles (pp. 249-252). Mahvah, NJ: Lawrence Erlbaum 
associates.

Vester, C. (2005). Learning styles and teaching. Retrieved June 1, 2010, from http://www.teaching English.org.Uk/think/methodology/learning styles

Zamanzade, V., Valizade, L., E., Fathi Azar, \& Aminaie, N. (2008). Nursing and midwifery students' learning styles in Tabriz Medical University. Research Journal of Biological Sciences, 3(2), 243-245.

\section{Appendix A: Paragon Learning Style Inventory, English Version}

For each of the 48 questions below select either "a" or "b" to indicate your answer. Please choose only one answer.

1. When you come to a new situation you usually

a. try it right away, and learn from doing

b. like to watch it first and try it later

2. Do you think people should be more

a. sensible and practical

b. imaginative and inspired

3. When you come to an uncertain situation

a. you usually trust your feelings more

Db. you usually trust your thinking more

4. Would you say you are

a. a little more serious

¿b. a little more easy-going

5. Do you spend most of your time

a. often in bigger groups and seldom alone

b. in smaller groups or alone

6. It is better to

a. be able to accept things

b. want to change things

7. Is it worse to

a. do mean things

b. do unfair things

8. Do you prefer when things are

a. planned and structured

b. spontaneous and unplanned

9. After a day spent with a lot of people do you

$\square$ a. feel energized and stimulated

$\square$ b. feel drained and like being alone

10. When you need to get something important done, you prefer to

$\square$ a. do it the way that has worked before

b. do it a new way that you just thought of

11. Which is a bigger compliment?

a. "he/she is really nice"

b. "he/she is really smart"

12. When it comes to time, are you more likely to

$\square$ a. usually be on time 
b. be pretty flexible

13. When you are in a group do you usually

$\square$ a. do a lot of the talking

b. mostly listen and talk a little

14. Are you more interested in

a. what really is

b. what can be

15. When you look at two things, you mostly notice

$\square$ a. how they are the same

Db. how they are different

16. Do you tend to get along better with

a. people who are a lot like you

b. lots of different types of people

17. Most other people seem to see you as

a. kind of out-going

b. kind of shy and reserved

18. When it comes to work that is very exact and detailed

a. it comes pretty easily to you

b. you tend to lose interest in it quickly

19. When your friends disagree, it is more important to you

a. to help them agree and come together

b. to help them come to the right answer

20. When you get-up in the morning

a. you know pretty much how your day will go

b. it seems every day is pretty different

21. When it comes to using the phone

$\square$ a. you use it a lot and make most of the calls

b. you use it most when others call you

22. When you work on group projects, do you prefer

$\square$ a. helping make sure the project gets done and works

b. helping come up with the ideas and plans

23. Others often describe you as a

a. warm-hearted person

b. cool-headed person

24. Which is more your way

a. to "do the right thing"

b. to "just do it"

25. When you talk to strangers you've just met you

a. talk pretty easily and at length

b. run out of things to say pretty quickly

26. When it comes to work you

$\square$ a. prefer steady effort and a regular routine 
b. work in spurts, really "on" then really "off"

27. Is it worse to be

a. too critical

b. too emotional

28. Would you rather have things

$\square$ a. finished and decided

b. open to change

29. When it comes to news at school, you seem

a. to find it out quickly

b. to be one of the last to know

30. Are you more likely to trust

a. your experience

b. your hunches

31. I prefer teachers who are more

a. caring and supportive

b. knowledgeable and expect a lot

32. Is it more your way to

a. finish one project before you start a new one

b. have lots of projects going at once

33. Which is more true of you? do you

a. too often act and talk without thinking much first

b. spend too much time thinking and not enough doing

34. Games would be more fair if kids

a. would just follow the rules

b. would just use "good sportsmanship"

35 . Is it usually easier for you to tell

a. how someone else is feeling

b. what someone else is thinking

36. Which is the more useful ability

a. to be able to organize and plan

b. to be able to adapt and make do

37. At a party or gathering

a. you do more of the introducing of others

b. others introduce you more

38. Do you think more about

a. what is going on right now

b. what will happen in the future

39. It is more your way to

a. usually show what you are feeling

b. usually not show your feelings

40. You are the kind of person who

a. needs to have things a certain way 
b. does it any old way

41. When you get done with an assignment

a. you feel like showing it to someone

b. you like to keep it to yourself

42. Things would be better if people were

a. more realistic

b. more imaginative

43. Would you say you are more concerned with

a. being appreciated by others

b. achieving something important

44. It is better that people

a. know what they want

b. keep an open-mind

45. Friday night after a long week you usually

a. feel like going to a party or going out

b. feel like renting a movie or relaxing

46. When you do a job, it's usually your approach to

a. start from the beginning, and go step-by-step

b. start anywhere, and figure it out as you go

47. When you tell a story, you mostly talk about

a. how the people involved were effected

b. what went on in general

48. You feel most comfortable when things are more

a. planned and you know what to expect

b. unplanned and flexible 